\title{
Os sentidos de ser enfermeiro estomaterapeuta: complexidades que envolvem a especialidade
}

\author{
The senses of being an enterostomal therapist nurse: complexities involved in the \\ specialty
}

\section{Los sentidos de ser enfermero estomaterapeuta: complejidades que implican la especialidad}

\begin{abstract}
Carolina Cabral Pereira da Costa ${ }^{1} *$, Norma Valéria Dantas de Oliveira Souza ${ }^{1}$, Ellen Marcia Peres ${ }^{1}$, Manoel Luis Cardoso Vieira², Jakeline Costa dos Santos ${ }^{1}$, Rafael Seabra Polidoro Cardoso'
\end{abstract}

ORCID IDS

Costa CCP (D) https://orcid.org/0000-0002-0365-7580

Souza NVDO (D) https://orcid.org/0000-0002-2936-3468

Peres EM (D) https://orcid.org/0000-0003-4262-6987

Vieira MLC (iD https://orcid.org/0000-0003-1614-5848

Santos JC (D) https://orcid.org/0000-0003-1872-320X

Cardoso RSP (D) https://orcid.org/0000-0002-7569-6714

\section{COMO CITAR}

Costa CCP; Souza NVDO; Peres EM; Vieira MLC; Santos JC; Cardoso RSP. Os sentidos de ser enfermeiro estomaterapeuta: complexidades que envolvem a especialidade. ESTIMA, Braz. J. Enterostomal Ther., 18, 2020: e0620. https://doi.org/10.30886/estima.v18.835_PT

\begin{abstract}
RESUMO
Objetivo: descrever os sentidos de ser estomaterapeuta considerando a complexidade do processo de cuidar de pessoas com feridas, estomias e incontinências. Método: Estudo de natureza qualitativa, do tipo descritivo-exploratório, realizado por meio de entrevista semiestruturada, entre os meses de janeiro a abril de 2018, com 22 egressos de um curso de Especialização em Enfermagem em Estomaterapia de uma universidade pública da região Sudeste, seguindo a técnica de snowball. Realizou-se, ainda, a pesquisa documental, a fim de complementar a análise dos dados. Resultados: Os egressos entrevistados relataram que ser estomaterapeuta é cuidar das pessoas que apresentam alguma ferida, estomia e/ou incontinência, ou seja, reconheceram a essência da especialidade. Destacaram que ser estomaterapeuta é cuidar de pessoas que podem ser marginalizadas/estigmatizadas pela sociedade, é trabalhar com foco na reabilitação do paciente, buscando sua reintegração social e independência e é saber ser empreendedor. Conclusão: O sentido de ser estomaterapeuta envolve inserir-se em uma especialidade que confere flexibilidade de atuação no mercado de trabalho e caráter empreendedor, o qual confere reconhecimento profissional e até satisfação financeira. Sugere-se, assim, que novos estudos sejam realizados nessa área, contribuindo para os campos da assistência, ensino, pesquisa e extensão.
\end{abstract}

DESCRITORES: Enfermagem; Estomaterapia; Educação em Enfermagem.

\section{ABSTRACT}

Objective: To describe the meanings of being an enterostomal therapist considering the complexity of the process of caring for people with wounds, stomas and incontinence. Method: A qualitative, descriptive-exploratory study, conducted through a semistructured interview, between the months of January to April 2018, with 22 graduates from a specialization course in Nursing in Enterostomal Therapy from a public university in the Southeast region, following the snowball technique. Documental research was also carried out in order to complement the data analysis. Results: The interviewed graduates reported that being an enterostomal

1.Universidade do Estado do Rio de Janeiro - Departamento de Enfermagem Médico-Cirúrgica - Rio de Janeiro (RJ), Brasil.

2.Universidade Federal do Rio de Janeiro - Instituto de Doenças do Tórax - Rio de Janeiro (RJ), Brasil.

*Autora correspondente: carolcuerj@hotmail.com

Recebido: Nov. 21, 2019 | Aceito: Abr. 6, 2020 
therapist is taking care of people who have a wound, stoma and/or incontinence, which means they recognized the essence of the specialty. They emphasized that being an enterostomal therapist is to care for people who may be marginalized/stigmatized by society, to work with a focus on the patient's rehabilitation, seeking social reintegration and independence, and to know how to be an entrepreneur. Conclusion: The meaning of being an enterostomal therapist involves being inserted in a specialty that provides flexibility in the job market and an entrepreneurial character, which gives professional recognition and even financial satisfaction. It is suggested, therefore, that further studies be carried out in this area, contributing to the fields of assistance, teaching, research and extension.

DESCRIPTORS: Nursing; Enterostomal therapy; Nursing education.

\section{RESUMEN}

Objetivos: Describir los sentidos de ser un estomaterapeuta considerándose la complejidad del proceso de cuidar de personas con heridas, estomías e incontinencias. Método: Estudio cualitativo, de tipo descriptivo-exploratorio, realizado mediante entrevista semiestructurada, entre los meses de enero a abril de 2018, con 22 egresados de un curso de Especialización en Enfermería en Estomatoterapia de una universidad pública de la región Sudeste de Brasil, siguiendo la técnica bola de nieve (snowball). También se realizó una investigación documental para complementar el análisis de los datos. Resultados: Los egresados entrevistados informaron que ser estomatoterapeuta es cuidar de personas que presentan alguna herida, estomía y/o incontinencia, es decir, reconocieron la esencia de la especialidad. Subrayaron que ser estomaterapeuta es cuidar de personas que pueden ser marginadas/estigmatizadas por la sociedade, es trabajar con foco en la rehabilitación del paciente, buscando su reintegración social e independencia y es saber ser un emprendedor. Conclusión: El sentido de ser estomaterapeuta implica insertarse en una especialidad que proporciona flexibilidad de actuación en el mercado laboral y carácter emprendedor, lo que concede reconocimiento profesional e incluso satisfacción financiera. Así, se sugiere que se realicen nuevos estudios en esta área, contribuyendo a los campos de asistencia, enseñanza, investigación y extensión.

DESCRIPTORES: Enfermería; Estomaterapia; Educación en Enfermería.

\section{INTRODUÇÃO}

Este estudo versa sobre o sentido de ser enfermeiro estomaterapeuta e as interfaces com o processo de cuidar.

Destaca-se, incialmente, que se entende como sentido, uma produção pessoal, fruto da apreensão individual dos significados coletivos, nas experiências cotidianas. A análise dos sentidos produzidos pelas pessoas deve considerar as relações com os significados construídos coletivamente e vice-versa ${ }^{1}$.

A introdução de novas tecnologias no mundo do trabalho em saúde tem modificado sua força de trabalho nesse setor, criando a necessidade de contratação de profissionais cada vez mais qualificados para as inovações dos meios diagnósticos e terapêuticos. Esse fenômeno amplia-se para o campo da enfermagem, já que um número cada vez maior de enfermeiros vem buscando o constante aperfeiçoamento e especialização por meio de cursos de pós-graduação ${ }^{2}$.

O momento da escolha de uma especialidade envolve muitos simbolismos e significações individuais e coletivas, o que não é uma tarefa fácil, como se acredita no senso comum. É multidimensional, complexa e plurideterminada por fatores pessoais, sociais, filosóficos, políticos e econômicos, dentre outros ${ }^{2}$.
Nessa perspectiva, evidencia-se um fenômeno peculiar que se caracteriza na procura cada vez maior pela estomaterapia como especialização de enfermeiros recém-egressos de cursos de graduação. Cabe salientar que tal especialidade é complexa, pois envolve uma atividade multidisciplinar, a utilização de diversas tecnologias e a prestação do cuidado em sua dimensão biopsicossocial ${ }^{2,3}$. Portanto é preciso desenvolver habilidades e competências singulares e especiais para atuar com segurança e excelência, garantindo assim, qualidade de vida às pessoas assistidas.

A estomaterapia é uma especialidade exclusiva dos enfermeiros cujo foco é o cuidado de pessoas com estomias, fístulas, tubos, drenos, feridas agudas e crônicas, além de incontinências anal e urinária. Ainda se destina a atividades e estratégias preventivas, terapêuticas e reabilitatórias, com vistas à melhoria da qualidade de vida da clientela $\operatorname{assistida~}^{2,3}$.

Verifica-se que tal especialidade se encontra em expansão nacional, uma vez que está presente em vários campos de atuação da enfermagem, extrapola as atividades assistenciais penetrando no ensino, na pesquisa, na administração, na assessoria e na consultoria. O estomaterapeuta pode atuar em serviços públicos e privados, ambulatórios, clínicas, consultórios especializados em estomaterapia e assistência domiciliar, além de ter a 
possibilidade de realizar o seu próprio empreendimento ${ }^{4}$, ganhando cada vez mais destaque no contexto do mundo do trabalho em saúde.

Para se consolidar na área da estomaterapia e ter satisfação e efetividade no seu processo laboral, um dos mais importantes pilares é o exercício da autonomia, que é imprescindível no mercado de trabalho, devido às transformações que vêm ocorrendo com o trabalho do enfermeiro no mundo globalizado.Assim, o estomaterapeuta necessita de autonomia para administrar a criatividade e resolutividade, gerando crescimento profissional ${ }^{5}$.

É importante considerar ainda a atuação desse profissional no cuidado à pessoa com lesões de pele. $\mathrm{O}$ tratamento e a prevenção de feridas, na maioria das vezes, encontram-se sob a responsabilidade do enfermeiro, possibilitando a avaliação e a prescrição das coberturas mais efetivas para o tratamento das lesões. Muitos estomaterapeutas são, frequentemente, convidados a compor a equipe da comissão de curativos das instituições, em decorrência de seus conhecimentos diferenciados no tratamento de pessoas com feridas, fato que confere, inclusive, maior autonomia na prática desse especialista ${ }^{4}$.

Destaca-se também a importância do estomaterapeuta na reabilitação da pessoa com incontinência, o qual vem ganhando cada vez mais espaço na prática clínica. De tal modo é a exigência do mercado de trabalho, a permanência de profissionais qualificados, empoderados e proativos, com a competência para rapidamente incorporar tecnologias e dar soluções às complexas questões dos processos de produção em saúde ${ }^{6}$.

Uma das justificativas para o presente estudo diz respeito às questões epidemiológicas e ao perfil das pessoas com estomias no Brasil, pois se tem uma elevação em seu quantitativo, relacionado, sobretudo, ao aumento das doenças que predispõem à cirurgia geradora de uma estomia, como o câncer colorretal e as doenças inflamatórias intestinais, sem contar com a alta incidência de estomias originadas de terapêuticas de traumas abdominais.

Ademais, a população brasileira se encontra em processo de envelhecimento e pode apresentar demandas relacionadas às condições crônicas de saúde e à área da estomaterapia, tais como lesões por pressão, estomias, drenos, cateteres, incontinências, pé diabético, úlceras vasculogênicas, o que justifica a importância de ampliar as discussões sobre os sentidos de ser estomaterapeuta e a complexidade do cuidado desenvolvido por esse especialista.

\section{OBJETIVO}

Descrever os sentidos de ser estomaterapeuta considerando a complexidade do processo de cuidar de pessoas com feridas, estomias e incontinências.

\section{MÉTODOS}

Trata-se de uma pesquisa de natureza qualitativa, do tipo descritiva-exploratória. O cenário deste estudo foi uma universidade da rede pública da região Sudeste do Brasil, onde são ministradas as aulas do curso de Pós-Graduação em Enfermagem em Estomaterapia. A coleta de dados ocorreu por meio de entrevista semiestruturada entre os meses de janeiro a abril de 2018, com 22 egressos desse curso de especialização. Ressalta-se que foram entrevistados 6 egressos da turma de 2013, 2 de 2012, 7 de 2011, 6 de 2010 e 1 de 2009.

A coleta de dados foi realizada pela autora principal desta pesquisa, seguindo a técnica de snowball, ou seja, cada participante indicou, pelo menos, um estomaterapeuta. Nesse sentido, a princípio, foram escolhidos três egressos de turmas em que se encontravam no critério temporal estabelecido. Foi solicitada aos primeiros egressos selecionados a indicação de outros egressos que estivessem incluídos nos critérios de seleção do estudo e assim sucessivamente.

O snowball (bola de neve) é uma técnica de amostragem que utiliza cadeias de referência, uma espécie de rede. Assim, os participantes iniciais do estudo indicam novos participantes, que, por sua vez, apontam outros novos participantes, e assim sucessivamente, até que seja alcançado o objetivo proposto, que é o "ponto de saturação", o qual é atingido quando os novos entrevistados passam a repetir os conteúdos já obtidos em entrevistas anteriores, sem acrescentar outros dados importantes à pesquisa ${ }^{7}$.

Realizou-se, ainda, uma pesquisa documental, que é uma técnica que permite ao pesquisador coletar dados de maneira indireta, por meio de fontes documentais selecionadas de acordo com o objeto e os objetivos do estudo ${ }^{8}$. Esta investigação possibilitou, nos meses de janeiro a março de 2018, a análise do conteúdo das ementas, do projeto político pedagógico, dos planejamentos das aulas e dos formulários, disponibilizados pela coordenação do curso de especialização em questão. 
Os critérios de seleção dos egressos seguiram os seguintes parâmetros: estarem trabalhando na enfermagem há pelo menos um ano e serem especialistas em estomaterapia por uma determinada universidade pública da região Sudeste do Brasil há, no mínimo, três anos (egressos do referido curso). Escolheu-se o tempo de um ano, por se considerar um recorte temporal suficiente para que os profissionais tenham apreendido o processo de trabalho, podendo apresentar seus pontos de vista sobre a área da estomaterapia. O recorte temporal para inclusão se justifica, pois recém-egressos, entendidos como aqueles formados há até três anos, ainda se encontram em processo de consolidação no mercado de trabalho, procurando uma colocação adequada aos seus anseios? ${ }^{9}$.

Já o critério estabelecido para exclusão foi: ser egresso da turma de 2007, uma vez que, à época, não havia registro formal referente aos dados telefônicos e eletrônicos, para captação das informações.

A partir dos critérios de inclusão e exclusão, considerou-se, então, o recorte temporal de seis anos, determinando como alvo populacional os egressos do curso de Especialização em Enfermagem em Estomaterapia em questão, de 2008 a 2013.

As entrevistas foram realizadas em local reservado e as informações coletadas foram gravadas por meio de um equipamento digital e, posteriormente, transcritas na íntegra pela autora principal, no editor de texto Microsoft Word. As entrevistas foram analisadas com base na técnica de análise temática de conteúdo ${ }^{10}$. A utilização dessa técnica fez emergir 1.784 unidades de registro (UR), representadas por 34 unidades de significação/temas. Destaca-se que 259 UR, o que corresponde a 14,49\% do total de UR construídas, permitiram apreender os sentidos que a especialidade revela para os egressos do curso de estomaterapia, considerando as especificidades do cuidado.

Para atender às exigências éticas, a pesquisa foi submetida à apreciação e aprovação do Comitê de Ética em Pesquisa e foi aprovada sob o número de parecer 2.314.626 (CAAE número 0107217.8.0000.5282). A fim de manter-se o sigilo com relação à identificação dos participantes do estudo, foi utilizada a letra E (estomaterapeuta), seguido de um número cardinal que representou a ordem cronológica de realização das entrevistas.

\section{RESULTADOS}

Os resultados trataram de um cuidado diferenciado do estomaterapeuta a partir de uma abordagem holística. Além disso, outro tema que emergiu nas entrevistas foi o significado/sentido de ser estomaterapeuta e sua formação diferenciada. Os participantes destacaram ainda o caráter reabilitatório da especialidade e a vivência com pacientes estigmatizados, bem como a responsabilidade do estomaterapeuta em desconstruir os estigmas. Também se constatou, nas entrevistas, o papel empreendedor do estomaterapeuta.

Os depoimentos dos egressos entrevistados evidenciaram aspectos importantes que traduzem o sentido de ser estomaterapeuta, associados ao cuidado a partir de um olhar holístico para o cliente:

"Eu acho que ser enfermeiro estomaterapeuta é a gente colocar na prática aquilo que a gente aprendeu, de ter um olhar holístico, ou seja, o que aquela ferida, o que aquele estoma traz, para vida daquela pessoa, a questão social, a questão emocional e etc.” (E1)

"É você olhar o indivíduo no seu todo, entender quais são as necessidades que ele tem, é entender aonde você pode ajudar. E, no fato de eu ser estomaterapeuta, eu consigo fazer isso, consigo olhar o indivíduo no seu todo." (E6)

"Porque as patologias ou as situações que levam às condições do paciente necessitar de cuidados ligados à área de estomaterapia requerem do enfermeiro uma atenção integral, holística, às suas condições de vida, de patologia no momento." (E21)

Os participantes destacaram que ser estomaterapeuta é cuidar dos pacientes que apresentam alguma ferida, estomia e/ou incontinência, ou seja, reconheceram a essência da especialidade:

"Ser estomaterapeuta é abranger as feridas, estomas, incontinência. Eu me considero assim uma especialista nessa área, atuante, e que consigo fazer a diferença por ser assim tão específico.”(E17) 
"Ser enfermeiro estomaterapeuta é ser um especialista conferido ao enfermeiro que deseja se aprofundar na área de feridas, estomas, incontinências e a escolha da especialidade, denota significados muito distintos para o ser enfermeiro." (E21)

Reforça-se que, durante o processo de análise documental das ementas do referido curso de especialização, identificou-se a preocupação em abordar as três áreas do saber que envolvem a estomaterapia de forma consistente e efetiva, o que favorece o processo de formação do futuro especialista, pois inicia com o eixo relacionado ao cuidado às pessoas com feridas, perpassando pelo módulo de estomia, a fim de concluir com a abordagem às incontinências.

O curso em questão também é constituído por dois módulos de ensino geral que tratam de aspectos éticos, da abordagem psicossocial, da educação em saúde e para o autocuidado, de gerência relacionada à estomaterapia, entre outros, os quais dão sustentação a uma prática integral e holística desse especialista.

Os participantes destacaram o fato de o estomaterapeuta cuidar de pessoas que podem ser marginalizadas/ estigmatizadas pela sociedade como outro fator imperioso que contribui para conferir o sentido da especialidade, conforme evidenciado nos depoimentos:

"A gente lida com pessoas que são incontinentes, e as feridas que têm odor, que não são bem vistas pelas outras pessoas, coisas que ninguém quer tocar. As pessoas se afastam um pouco e a gente não. A tendência é que esses pacientes fiquem mais isolados em relação às outras pessoas." (E01)

"A estomaterapia me ajudou muito a compreender e lidar com preconceitos e estigmas sociais. Ser estomaterapeuta me ajudou a entender o cliente porque eles falam: 'Ah, eu agora sou diferente dos outros'. Ele é diferente, sim, mas ao mesmo tempo, ele não deixou de ser um ser humano. E a gente consegue fazer com que eles se aceitem um pouco mais. Principalmente aqueles pacientes que vão ficar com estomia definitiva, já que muitos desses pacientes são deixados de lado pela maioria dos profissionais. Então, ser estomaterapeuta é cuidar das pessoas que se sentem excluídas.” (E20)

Apesar de ter sido referenciado por apenas um participante, cabe destacar que ser estomaterapeuta é trabalhar com foco na reabilitação do paciente, buscando o autocuidado, sua reintegração social e independência.

“Ser um enfermeiro estomaterapeuta é principalmente atuar na reabilitação dos pacientes, já que, muitas vezes, os profissionais em geral não conseguem ter aquela visão diferenciada, e perceber manifestações como a depressão. Ser um enfermeiro estomaterapeuta, hoje, para mim, me traz muito orgulho, porque eu consigo ver um tratamento diferenciado para esses pacientes, auxiliá-los melhor na reabilitação. Fazer com que eles se tornem independentes, e não dependentes do profissional de saúde. É claro que eles precisam de um cuidado, eles precisam de um acompanhamento, mas é fundamental fazer com que o paciente se sinta independente, para que possa continuar com a vida dele, normalmente." (E20)

Nos depoimentos, os participantes enalteceram que o sentido de ser estomaterapeuta é saber ser empreendedor:

“Ser estomaterapeuta é empreender e eu consigo, pois tenho meu próprio negócio. Eu tenho os meus atendimentos particulares. A gente consegue esse investimento.”(E07)

"E também ter foco no empreendedorismo, porque o estomaterapeuta tem grande poder empreendedor, ele pode trabalhar até como freelancer, trabalhar dentro de empresa demonstrando os produtos, abrir um consultório, uma clínica." (E08)

Destaca-se que o referido Curso de Especialização em Estomaterapia encontra-se em consonância com as novas perspectivas de mercado. Isso porque, após análise documental das suas ementas, verificou-se que são ministradas aulas que abordam marketing, empreendedorismo e relacionamento interpessoal no contexto da estomaterapia; três importantes temáticas que auxiliam o especialista a refletir sobre independência, autonomia e estratégias de atuação que vislumbram processos de trabalhos diferenciados, porém pautados na ética e na cientificidade.

\section{DISCUSSÃO}

A essência do trabalho do enfermeiro e da enfermagem é o cuidado, que promove um contato mais próximo com o 
cliente em relação às suas próprias necessidades de saúde, engloba atos, comportamentos e atitudes, fruto, muitas vezes, das relações estabelecidas entre o usuário e o profissional. Além disso, é uma ação que compreende um olhar atento, a percepção dos variados sentimentos e atitudes de atenção, zelo e responsabilização para com o cliente envolvido no processo de cuidar ${ }^{11,12}$.

Nessa perspectiva, a humanização da assistência em saúde tem sido um tema muito valorizado pelas instituições e pelo universo acadêmico, pois existe uma preocupação em oferecer um cuidado integral ao cliente, considerando-o em sua totalidade. $\mathrm{O}$ cuidar adquire uma dimensão mais abrangente, enfatizando as necessidades biológicas emocionais, psicológicas, sociais e espirituais, o que favorece o panorama do cuidado holístico ${ }^{13}$.

O processo de cuidar vai ao encontro do compromisso de manter a singularidade do ser cuidado, já que se trata de um momento de preocupação, sensibilidade e interesse, em que o respeito e a ética se tornam diferenciais. A consciência do cuidado deve abarcar a capacidade de decisão e o pensamento crítico-reflexivo, para diferenciar o cuidado da simples realização de procedimentos técnicos ${ }^{14}$.

O olhar holístico no processo de cuidado foi destaque nas falas dos entrevistados, quando se indagou o sentido de ser estomaterapeuta. Isso porque se sabe que o enfermeiro estomaterapeuta deve liderar o cuidado holístico e interdisciplinar, priorizar a qualidade assistencial diferenciada que congrega conhecimentos constantemente atualizados e baseados em evidências científicas, voltados para as necessidades da clientela ${ }^{15}$.

Como o estomaterapeuta cuida de uma clientela que vivencia inúmeras dúvidas, inseguranças e medos frente a uma nova condição de vida, que pode ser temporária ou não, além da possível presença de lesões, as quais, muitas vezes, demoram anos para cicatrizar, esse profissional deve estar atento para oferecer um cuidado que vá além da estomia, ferida ou queixa de incontinência, abrangendo o entendimento de todo o processo biopsicossocial ${ }^{15}$.

Por essa razão, o estomaterapeuta utiliza variadas alternativas de cuidados para assistir adequadamente às pessoas, uma vez que estas demandam apoio físico e também psicossocial, até porque muitas das intervenções podem ser definitivas e comprometer inclusive a qualidade de vida ${ }^{15}$.

A pessoa que apresenta uma estomia (temporária ou definitiva), lesões de pele, incontinências e/ou fístulas requer um cuidado diferenciado e precisa ser vista como um ser humano singular, dinâmico e complexo que necessita de apoio que vai além das intervenções tradicionais, que dizem respeito à realização de técnicas somente.

Constatou-se, nos depoimentos, um sentido muito especial conferido ao estomaterapeuta por ser um especialista capaz de atuar em distintas etapas do processo de cuidar, abordar o cliente em suas múltiplas dimensões, sendo capaz de valorizar a qualidade de vida do ser humano.

Conforme apresentado nos resultados, verifica-se que a estomaterapia é uma especialidade que demanda uma formação diferenciada e, por essa razão, segue diretrizes de ensino nacionais, regulamentadas pelo Ministério de Educação e Cultura, pelos órgãos formadores, pela Associação Brasileira de Estomaterapia (Sobest) e por entidades cientificas internacionais. No Brasil, a estomaterapia é considerada um curso de pós-graduação lato sensu - nível de especialização. Quanto às normas internacionais, o ensino também deve ser norteado pelas diretrizes propostas pelo World Council of Enterostomal Therapists (WCET), a fim de obter reconhecimento de expert em nível global ${ }^{16}$.

Um dos principais papeis do WCET é a regulamentação da educação em estomaterapia no mundo. Por meio do seu Comitê de Educação são criadas as diretrizes curriculares para o credenciamento de novos cursos, bem como recredenciamento dos cursos em andamento. $\mathrm{O}$ objetivo dessas diretrizes é uniformizar o ensino da especialidade, com validade a nível local ou nacional e garantir a qualidade da educação em estomaterapia ${ }^{16}$.

Salienta-se que a Sobest disponibiliza orientação curricular, propicia assessoria e consultoria para as instituições de ensino que se mostrem interessadas em implantar cursos de enfermagem em estomaterapia. A acreditação proposta tanto pela Sobest quanto pelo WCET objetiva garantir uma formação com padrão internacional pautada nos preceitos da formação qualificada do especialista ${ }^{4}$.

Sabe-se que a estomaterapia é uma especialidade que cuida de pessoas que passam por algumas adversidades e, por vezes, modificações em seus corpos, de forma temporária ou definitiva, que podem fragilizar as relações interpessoais, ocasionando desgaste físico e emocional. Nesse contexto, a sociedade acaba, muitas vezes, excluindo essa pessoa com deficiência e/ou necessidades diferenciadas do mercado de trabalho e dos ambientes social e familiar ${ }^{17}$.

Nesse sentido, o estomaterapeuta busca orientar e compreender essas pessoas em suas diversas perspectivas, permitindo que se aceitem um pouco mais diante da nova 
realidade vivenciada. No entanto a reinserção social é cercada de barreira e preconceitos, pois muitos ambientes de trabalho não possuem adaptação na infraestrutura para receber as pessoas com estomia e não há um programa que as capacite para uma nova atividade laboral, fazendo com que se sintam frustradas e excluídas da sociedade ${ }^{17}$.

Para a pessoa que se encontra em um momento de fragilidade, com uma estomia, uma ferida e até mesmo incontinente, engajar-se em atividades que lhes possibilitem retornar ao ambiente laboral e ao convívio social e familiar é de fundamental importância para a recuperação da autoestima e superação de preconceitos ${ }^{18}$.

Dada a magnitude do problema, o apoio dos membros da família, amigos e da instituição onde essa pessoa está inserida, torna-se muito relevante. Por essa razão, os egressos entrevistados neste estudo relataram que ser estomaterapeuta é viabilizar um processo de cuidado às pessoas que podem vir a ser estigmatizadas pela sociedade, como sendo um fator imperioso que favorece o sentido da especialidade. Portanto os estomaterapeutas devem se envolver com o processo de reabilitação e inclusão social das pessoas ou qualquer outra necessidade/demanda relacionada à área de estomaterapia, uma vez que o apoio e o incentivo constantes por parte desses profissionais são essenciais para a superação das barreiras encontradas no ambiente social e de trabalho ${ }^{17}$.

Cabe destacar que existe uma associação estreita entre a questão da exclusão social e a pessoa com estomia, um dos pilares do processo de cuidado relacionado à estomaterapia. Assim, sabe-se que muitas pessoas com estomias têm uma tendência ao isolamento, pois preferem manter em segredo sua condição de saúde e, por essa razão, afastam-se dos familiares e amigos, e até do ambiente laboral, por conta do estigma causado pela presença da estomia ${ }^{19}$.

Para favorecer a inclusão e a permanência no convívio social, o estomaterapeuta é fundamental na vida dessas pessoas, no sentido de planejar e implementar intervenções que possibilitem uma aproximação com tal realidade e a construção de novos significados ao evento patológicocirúrgico que pode ter afetado outras dimensões da vida ${ }^{19}$.

Acredita-se que, por isso, muitos dos depoimentos se voltaram para a relação entre o sentido da especialidade e o processo de cuidar de pessoas excluídas da sociedade como um ponto importante do processo de trabalho do profissional.

O processo de reabilitação é dinâmico, objetiva a recuperação das diversas dimensões da pessoa com alguma deficiência permanente ou temporária. Durante a análise documental, da dinâmica curricular do referido curso de estomaterapia, identificaram-se disciplinas que buscam oferecer subsídios ao especialista para o desenvolvimento de estratégias que favoreçam a habilidade de inclusão social. No conteúdo programático são contemplados os cuidados à pessoa com estomia para facilitar esse processo, momento em que se discute a assistência com vistas à reintegração em ambientes diversos e o processo reabilitatório, utilizando-se a autoirrigação e o sistema oclusor.

Dessa forma, cabe ao estomaterapeuta assistir direta e indiretamente ao cliente com ética, humanitude, competência clínica; desempenhar um papel decisivo dentro da equipe de saúde, com vistas à orientação e inclusão nas atividades de vida diária, de acordo com a sua capacidade funcional ${ }^{20}$; e buscar pela reabilitação e independência dessa pessoa.

A fim de que o paciente se sinta incluído socialmente, o estomaterapeuta também deve estimulá-lo à prática do autocuidado e, para tal, deve incluir as orientações que o permitam atuar como ator social e protagonista do seu processo saúde-doença.

As orientações oferecidas pelo estomaterapeuta são importantes e necessárias, uma vez que as práticas educativas por ele conduzidas contribuem para a inclusão social dos clientes sob seus cuidados. O processo educativo em saúde é compreendido como uma prática realizada junto a grupos sociais a partir de campos de conhecimento que compõem as áreas interdisciplinares da saúde e da educação e, até bem pouco tempo atrás, muitos profissionais, inclusive os enfermeiros, adotavam em suas práticas educativas o papel de meros transmissores de informações, priorizando as orientações voltadas aos cuidados biologicistas ${ }^{21}$. No entanto esse perfil tem se modificado, sobretudo porque o enfermeiro ampliou o escopo de abordagem para o autocuidado do paciente para ajudá-lo a conquistar autonomia.

Embora algumas práticas educativas ainda apresentem resquícios do modelo biologicista, a maioria delas considera as transformações psicossociais que ocorrem na vida das pessoas, o que na área de estomaterapia é primordial como incentivo ao autocuidado, à reabilitação e à reinserção social ${ }^{20}$.

O curso de especialização em questão valoriza as práticas educativas e as discute tanto em termos teóricos quanto práticos. Destaca-se que, no ano de 2018, foram criados em um dos campos de estágio - a Clínica de Estomaterapia unidade do complexo da universidade, dois grupos de apoio e educação para o autocuidado, intitulados ESTOUBEST e METAMORFOSE. 
O ESTOUBEST é um grupo direcionado para as pessoas com estomias e o METAMORFOSE para as pessoas cadeirantes, uma vez que muitas delas apresentam incontinência, retenção urinária, lesões de pele e estomias. Os integrantes dos grupos reúnem-se uma vez por mês e os especializandos em estomaterapia realizam atividades educativas e dão apoio emocional às pessoas que procuram a clínica.

Nos depoimentos, os entrevistados destacaram que ser estomaterapeuta é também empreender. O empreendedorismo pode ser entendido como a criação ou aperfeiçoamento de algo, com o intuito de propiciar benefícios para os indivíduos e para a sociedade, tendo avançado nas últimas décadas em decorrência das transformações econômicas, inovações tecnológicas e da globalização ${ }^{22}$.

O empreendedorismo destaca-se na área da enfermagem como uma opção de carreira,já que o enfermeiro precisa conhecer suas diversas competências, ousar para explorar as oportunidades e alcançar espaços inovadores, tornando-se um protagonista de novos campos e práticas de atuação profissional ${ }^{23}$.

Adiciona-se, assim, um olhar diferente à produção de novos serviços, tornando o enfermeiro um profissional capacitado a vender seus serviços e a inovar suas atividades em qualquer cenário de atuação, renovando o "ser" enfermeiro, propiciando, na maioria das vezes, o tão almejado reconhecimento profissional e a satisfação financeira ${ }^{24}$.

Ressalta-se que, durante muitos anos no Brasil, o fato de se concluir apenas o curso de graduação já carregava a garantia de emprego e de estabilidade financeira, uma vez que não se tinha concorrência e competitividade, em decorrência da carência de profissionais e pelo nível de exigência do mercado de trabalho ser menor do que nos dias de hoje ${ }^{24}$.

Esse contexto vem mudando, tendo em vista que a população tem tido mais o acesso à informação, e a procura pelos serviços de saúde não tem sido somente em busca da cura, mas também como estratégia de prevenção. Isso faz com que os profissionais tenham que se manter atualizados e passem a se reinventar dentro da sua profissão. Por isso os enfermeiros têm investido em especializações para o desenvolvimento e incremento de sua carreira, o que gera concorrência e competitividade no mercado de trabalho, o qual, dependendo da região, encontra-se saturado ${ }^{24}$.

O empreendedor é um líder que produz uma visão do que é possível ser realizado, buscando atrair pessoas para atuar dentro daquela visão e transformá-la em realidade. O Brasil é apontado como um país empreendedor na formação de especialistas ${ }^{24}$, os estomaterapeutas dentre eles, uma vez que têm transformado paradigmas na assistência e no ensino, em decorrência de suas características empreendedoras e inovadoras no processo de cuidar, tendo autonomia, respeito dos clientes e satisfação em exercer a enfermagem com excelência.

Enquanto especialista, o enfermeiro tem difundido sua prática profissional por meio da assistência prestada, da produção científica, do ensino de graduação e pós-graduação e por meio dos serviços e assessorias/consultorias realizadas. Ressalta-se que a área de consultoria técnica, principalmente junto às empresas produtoras de materiais especializados na área de estomaterapia, vem apresentando amplo crescimento, além da auditoria especializada.

A atividade autônoma e empreendedora tem adquirido maior amplitude na prática da enfermagem com o surgimento dos primeiros "consultórios e clínicas" de enfermagem, serviços que foram criados com o propósito de desenvolver os cuidados que podem ser realizados em ambiente extra-hospitalar ${ }^{25} \mathrm{e}$, inclusive, aqueles relativos aos cuidados especializados, destacando-se os que necessitam de um saber específico e, por vezes, centrado em aspectos não tão amplamente divulgados, como a estomaterapia.

\section{CONCLUSÕES}

Este estudo possibilitou constatar os vários sentidos de ser estomaterapeuta considerando a complexidade do processo de cuidar de pessoas com feridas, estomias e incontinências. Identificou-se que há o sentido de ser um profissional com uma perspectiva holística do ser humano; que tem relevância na desconstrução do estigma social que vivenciam essas pessoas; que um dos sentidos de sua atuação é a reabilitação e inclusão social da clientela assistida.

Enfatizou-se, ainda, uma perspectiva que dá sentido a uma especialidade autônoma e que permite o atendimento domiciliar, possibilitando um novo campo de atuação para o especialista. Portanto o significado de ser estomaterapeuta envolve inserir-se em uma especialidade que confere flexibilidade de atuação no mercado de trabalho. Outra questão destacada foi o caráter empreendedor da especialidade, conferindo reconhecimento profissional e até satisfação financeira.

Entende-se como uma das limitações deste estudo o fato de se restringir à realidade de um curso de especialização, porém já se consegue perceber a necessidade da realização 
de novas pesquisas envolvendo egressos de outros cursos de estomaterapia, não se esgotando aqui as discussões.

Acredita-se que este estudo impulsione o surgimento de outras pesquisas, contribuindo ainda mais para os campos da assistência, ensino, pesquisa e extensão, a partir das discussões que traduzem o sentido de ser estomaterapeuta, com o propósito de valorizar a especialidade, a qual encontra-se em crescimento.

\section{CONTRIBUIÇÃO DOS AUTORES}

\author{
Conceitualização; Costa CCP e Souza NVDO;
} Metodologia; Costa CCP e Souza NVDO; Redação Primeira versão; Costa CCP, Souza NVD, Peres EM e Vieira MLC; Redação - Revisão \& Edição; Costa CCP, Souza NVDO, Peres EM, Vieira MLC, Santos JC e Cardoso RSP; Supervisão: Costa CCP e Souza NVDO.

\section{REFERÊNCIAS}

1. Coutinho MC. Sentidos do trabalho contemporâneo: as trajetórias identitárias como estratégia de investigação. Cad Psicol Soc Trab. 2009;12(2):189-202. https://doi. org/10.11606/issn.1981-0490.v12i2p189-202

2. Valente GSC, Vana LO, Neves IG. Las especialidades y los vínculos con la formación continua del enfermero: repercusiones para la actuación en el municipio de Rio de Janeiro. Enf Global. 2010;9(2):1-12.

3. Doughty D. History of WOC(ET) nursing education. J Wound Ostomy Cont Nurs. 2013;40(2):127-9. https://doi. org/10.1097/WON.0b013e3182850764

4. [Sobest] Associação Brasileira de Estomaterapia. Estomaterapia [Internet]. 2020 [citado em 15 Mar. 2020]. Disponível em: http://www.sobest.org.br/texto/8

5. Bonfada MS, Pinno C, Camponogara S. Potentialities and limits of nursing autonomy in a hospital environment. Rev Enferm UFPE on line. 2018;12(8):2235-46. https://doi.org/10.5205/19818963-v12i8a234915p2235-2246-2018

6. Santos Él, Oliveira JGAD, Ramos RS, Silva ACSS, Belém LS, Silva AL. Facilidades e dificuldades à autonomia profissional de enfermeiros no cuidado de pessoas com feridas: estudo de representações sociais. ESTIMA, Braz J Enterostomal Ther. 2017;15(1):3-9. https://doi. org/10.5327/Z1806-3144201700010002

7. Albuquerque EM. Avaliação da técnica de amostragem "respondent-driven sampling" na estimação de prevalências de doenças transmissíveis em populações organizadas em redes complexas [dissertação]. [Rio de Janeiro]: Escola Nacional de Saúde Pública Sérgio Arouca. Fundação Oswaldo Cruz; 2009.

8. Kripka RML, Scheller M, Bonotto DL. La investigación documental sobre la investigación cualitativa: conceptos y caracterización. Rev Investig UNAD. 2015;14(2):55-73. https://doi.org/10.22490/25391887.1455

9. D'Avila TB. Satisfação no trabalho de enfermeiros recémegressos [dissertação]. [Rio de Janeiro]. Universidade Federal do Estado do Rio de Janeiro; 2012.

10. Bardin L. Análise de conteúdo. Lisboa: Edições 70; 2011.
11. Santos AG, Monteiro CFS, Nunes BMVT, Benício CDAV, Nogueira LT. O cuidado em enfermagem analisado segundo a essência do cuidado de Martin Heidegger. Rev Cubana de Enferm. 2017;33(3).

12. Monteiro PV, Almeida ANS, Pereira MLD, Freitas MC, Guedes MVC, Silva LF. Quando cuidar do corpo não é suficiente: a dimensão emocional do cuidado de enfermagem. REME - Rev Min En. 2016;20:e957. https:// doi.org/10.5935/1415-2762.20160026

13. Evangelista CB, Lopes MEL, Costa SFG, Abrão FMS, Batista PSS, Oliveira RC. Espiritualidade no cuidar de pacientes em cuidados paliativos: Um estudo com enfermeiros. Esc Anna Nery. 2016;20(1):176-82.

14. Salviano MEM, Nascimento PDFS, Paula MA, Vieira CS, Frison SS, Maia MA, et al. Epistemologia do cuidado de enfermagem: uma reflexão sobre suas bases. Rev Bras Enferm. 2016;69(6):1240-5. https://doi. org/10.1590/0034-7167-2016-0331

15. Shoji S, Souza NVDO, Mauricio VC, Costa CCP, Alves FT. O cuidado de enfermagem em Estomaterapia e o uso das tecnologias. ESTIMA, Braz J Enterostomal Ther. 2017;15(3):169-77. https://doi.org/10.5327/Z18063144201700030008

16. Hibbert D. O WCET® \& Educação Global em Enfermagem em Estomaterapia. ESTIMA, Braz J Enterostomal Ther. 2019;17:e2119. https://doi.org/10.30886/estima. v17.807_PT

17. Mauricio VC, Souza NVDO. Conhecimento de pessoas estomizadas acerca dos aspectos legais relacionados à inclusão laboral. ESTIMA, Braz J Enterostomal Ther. 2015;13(4).

18. Mota MS, Gomes GC, Petuco VM. Repercussions in the living process of people with stomas. Texto Contexto - Enferm. 2016;25(1):e1260014. https://doi. org/10.1590/0104-070720160001260014

19. Mendonça SN, Lameira CC, Souza NVDO, Costa CCP, Mauricio VC, Silva PAS. Orientações de enfermagem e implicações para a qualidade de vida de pessoas estomizadas. Rev Enferm UFPE on line. 2015;9(1 Suppl):296-304. 
20. Mauricio VC, Souza NVDO, Costa CCP, Dias MO. The view of nurses about educational practices targeted at people with a stoma. Esc Anna Nery. 2017;21(4):e20170003. https://doi.org/10.1590/2177-9465-ean-2017-0003

21. Mauricio VC. Processo educativo desenvolvido por enfermeiros voltado para inclusão laboral de pessoas com estomia [tese]. [Rio de Janeiro]: Faculdade de Enfermagem, Universidade do Estado do Rio de Janeiro; 2015.

22. Almeida RC, Chaves M. Empreendedorismo como escopo de diretrizes políticas da União Europeia no âmbito do ensino superior. Educ Pesqui. 2015;41(2):513-26. https://doi.org/10.1590/s1517-97022015041779
23. Andrade AC, Dal Ben LW, Sanna MC. Empreendedorismo na enfermagem: panorama das empresas no estado de São Paulo. Rev Bras Enferm. 2015;68(1):40-4. https://doi. org/10.1590/0034-7167.2015680106p

24. SilvaACP, Valente GLC, Valente GSC. Oempreendedorismo como uma ferramenta para atuação do enfermeiro. Rev Enferm UFPE on line. 2017;11(4):1595-602.

25. Santos Él, Alves YR, Silva ACSS, Gomes AMT. Autonomia profissional e enfermagem: representações de profissionais de saúde. Rev Gaúcha Enferm. 2017;38(1):e59033. https:// doi.org/10.1590/1983-1447.2017.01.59033 